\title{
A Celebration of the Work of Professor Tony Kelly ScD FRS FREng PhD CBE DL
}

\author{
P. W. R Beaumont • Costas Soutis • Alma Hodzic
}

Received: 23 August 2013 / Accepted: 8 September 2013 /Published online: 13 October 2013

(C) Springer Science+Business Media Dordrecht 2013

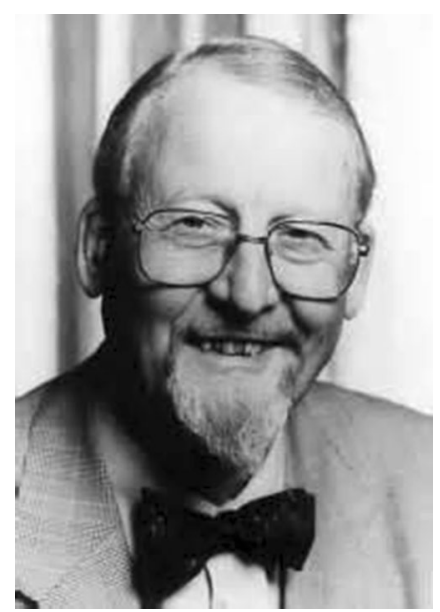

Emeritus Professor \& Distinguished Research Fellow at Cambridge University, Extraordinary Fellow of Churchill College, Cambridge \& Vice-Chancellor of the University of Surrey (retired)

Fellow of the Royal Society, Fellow of the Royal Academy of Engineering, Foreign Associate of the US National Academy of Engineering, Fellow of the Institute of Physics, Fellow of the Institution of Materials Mining \& Metallurgy (past President)

\section{A collection of invited papers to mark his 85th birthday year}

In the "swinging sixties", a fashionable professor at Cambridge, Alan Cottrell, often gave invited lectures at The Royal Society. On such an occasion, it was usual of him to ask his young

P. W. R. Beaumont $(\bowtie)$

University Of Cambridge, Cambridge, UK

e-mail: pwrb@eng.cam.ac.uk

C. Soutis

University of Manchester, Manchester, England

A. Hodzic

University of Sheffield, Sheffield, England 
lecturer Tony Kelly, also in the Metallurgy Department, to consider the script before presenting it. In a discourse delivered to the Royal Society on 15th June 1960, Alan enunciated the principle of fibre reinforcement: "No, the practical approach is to admit the existence of cracks and notches and to try to render them innocuous. If there is a transverse notch cutting across a parallel array of fibres in a rod of some material like adhesive, the forces from the cut fibres can be transmitted to the intact fibres close to the notch tip only by passing as shearing forces through layers of the adhesive". He continued: "If this adhesive has a fairly low resistance to shear ... it will then be incapable of focussing the transmitted forces sharply...There is a tremendous opportunity for developing this principle further using fibres of very strong atomic forces like oxides and carbides".

This was "music" to Tony's ear. With his interest and knowledge of ceramics, he recognised immediately that the oxides and the carbides would make ideal reinforcements. Tony and his earliest research students were perfectly placed in that they were already elucidating the principles of the strengthening of metals and yet were lucky enough to spot the advantages of non-metallic solids as the major strengthening agent. Tony began by asking his first research assistant, Bill Tyson from Canada, to validate or otherwise Alan's idea by using a metallic matrix as the adhesive. From this work, Tony and Bill produced what could be called the colligative mechanical properties of an aligned fibre-reinforced system; the contribution each phase makes to overall strength; how it depended on volume fraction; and importantly upon the ratio of length to diameter of the fibre. Furthermore, they found a new means of dissipating energy...fibre pull-out.

But there was one more discovery still to make with Tony's second research graduate, George Cooper, which was that a crack could not extend if faced with an interface which yielded easily in shear ... Cottrell's point above. However, it was not until both Tony and George went to the NPL at Teddington, England did they discover the principle of multiple cracking. The actual experiment was to incorporate silica fibres coated with carbon having a unique strain to failure of $4 \%$ into a resin with a strain to failure of $6 \%$ at room temperature and $1 \%$ at $77 \mathrm{~K}$. The contrast between the failure strains of fibre and matrix at the extremes of temperature is patently obvious. The difference in shape of the two load extension curves in tension was striking.

One of the components breaks in a series of parallel cracks while the other remains in tact and bears the load. Furthermore, the high elongation phase need not be continuous. Here, indeed, was a very striking phenomenon; they had produced ductility in a non-ductile material system. To produce ductility with a metal matrix is common place, but to produce it in a totally brittle system, that is something special. Tony and George were the first to analyse such behaviour and the first to name it...multiple cracking.

Beginning with his first two research students, Tony had discovered totally separate new methods of dissipating energy in composites, what the mechanicians call resistance to cracking, which we call toughness. Both were vital in understanding the materials science of composites, which is otherwise a very engineering discipline. Now, fragility of a material could be overcome by the incorporation of brittle fibres of oxides or carbides, for instance. By these means are engineering ceramics toughened.

The key that unlocked the secret of toughened ceramics (and other brittle materials like the adhesives) had been found, whether by laminating or by planar matting, or of oxide layers on metal surfaces, or of protective coatings and it is of the utmost importance. Controlling the phenomena of micro-cracking in composites determines whether or not glasses or ceramics are to be used in gas turbine engines as Cottrell once opined. Today, we think of large carbon fibre structures of the Airbus A380 or of Boeing's Dreamliner 787. 
As Tony has said to audiences, "those methods of dissipating energy in or around a crack were discovered by experiment; they were not predicted. They illustrate the central dogma that new materials are always discovered experimentally. They are not predicted".

The fact that Tony Kelly would reach 85 in 2013 had not escaped the notice of us, which inspired the occasion of the Cambridge-Sheffield-Manchester Universities combined meetings on "Deformation and Fracture of Composites" and "Structural Integrity and Multiscale Modelling of Engineering Composites" at Queens' College, Cambridge, April 8-11th, 2013. It was decided that the celebration would take the form of a College Feast and technical Meeting, consisting essentially of papers presented by distinguished scientists and engineers whose research over the years has been influenced in one way or another by the insightful work of Tony. Other papers were chosen that broadly surveyed the position of engineering composites today in which Tony remains so powerful a force.

Some of the papers presented were nostalgic by surveying the contributions made by Tony, (Bill Tyson was present at the feast), in so many fields, and progressive by indicating how it had been possible to develop engineering composites from such beginnings more than 50 years ago. Tony himself participated in most of the Meeting sessions, showing flair and imagination and capability for originality despite having suffered a stroke only a few weeks earlier on one of his lecture tours of Australia.

This special issue of Applied Composite Materials contains a selection of those contributions to the combined meetings of Deformation and Fracture of Composites (DFC-12) and Structural Integrity and Multi-scale Modelling of Engineering Composites (SI-6).

Co-edited by:

Peter Beaumont

University of Cambridge

Costas Soutis

University of Manchester

Alma Hodzic

University of Sheffield 